\title{
Do Polish doctors suffer from occupational burnout syndrome? An attempt to find an answer - Pilot study
}

\author{
Marta Makara-Studzińska ${ }^{1, A, E-F \oplus}$, Maciej Załuski2 ${ }^{2, C-D \oplus}$, Aneta Tylec ${ }^{3, A-C \oplus}$, Lech Panasiuk ${ }^{4, E-F} \oplus$ \\ ${ }^{1}$ Division of Health Psychology, Faculty of Health Sciences, Collegium Medicum, Jagiellonian University, Kraków, Poland \\ ${ }^{2}$ Collegium Medicum, Jagiellonian University, Kraków, Poland \\ ${ }^{3}$ The Second Psychiatry and Psychiatric Rehabilitation Clinic, Medical University, Lublin, Poland \\ ${ }^{4}$ Institute of Rural Health, Lublin, Poland \\ A - Research concept and design, B - Collection and/or assembly of data, C - Data analysis and interpretation, \\ $D$ - Writing the article, $E$ - Critical revision of the article, $F$ - Final approval of article
}

Makara-Studzińska M, Załuski M, Tylec A, Panasiuk L. Do Polish doctors suffer from occupational burnout syndrome? An attempt to find an answer - Pilot study. Ann Agric Environ Med. 2019; 26(1): 191-197. doi: 10.26444/aaem/105392

\section{Abstract}

Introduction and objective. A nationwide survey, carried out in Poland in 2013, showed that $42 \%$ of an examined group of doctors reported occupational burnout syndrome (OBS). The phenomenon of OBS among medical personnel shows a relationship with perceived stress scale (PSS) scores. The aim of the study was to estimate the prevalence of OBS in a group of Polish doctors, and the relationship with selected risk factors and personal resources.

Materials and method. A cross-sectional study using quantitative methodology was used with the application of a questionnaire method and correlation design. Questionnaires were administered to 318 doctors (42 different specialties) working in medical facilities in Poland. All participants in the study completed two standardized questionnaires: Link Burnout Questionnaire (LBQ), Perceived Stress Scale (PSS), and responded to the questions on a proprietary questionnaire. ANOVA variance analysis and analysis of regression was performed.

Results. The results of the measurement of four aspects of occupational burnout: psychophysical exhaustion (PE), commitment to relationships with patients (CP), effectiveness in performed work (EW), and existential expectations (EE), were in the medium and high levels range. Every second medical doctor who participated in the research declared a high degree of occupational burnout in each of the aspects of OBS. The high level of PSS scores, the large number of duties per month, the short work experience (years of employment) and the low number of holiday leaves, were the predictors of occupational burnout in the group of doctors taking part in the study.

Conclusions. The prevalence of the signs of OBS among Polish doctors is consistent with the results of research in other countries. Failures in the interventions taken to reduce stress seem to co-exist with the severity of signs of burnout.

\section{Key words}

burnout syndrome, physicians, occupational stress, psychological processes

\section{INTRODUCTION}

The data from scientific research indicate a progressive increase in burden for healthcare staff, who physically and mentally suffer from the risk of chronic occupational stress $[1,2]$. Healthcare institutions require from doctors perfectionism, the suppression of emotional sensitivity and delayed gratification from work [3]. They are expected to take effectively correct medical and ethically difficult decisions, e.g. regarding the discontinuance of treatment for economic reasons [4], to continuously improve their professional skills and interpersonal competence.

The list of stressors associated with the medical professions is very long, among them those connected with pressure of time and with control of performed work, disadvantageous working hours (24 hours) a day, a disturbed sleep pattern and waking state as the result of a large number of night- duties in a month, the risk of losing one's autonomy at work and the ability to make one's own decisions, as well as the disturbance

Addres for correspondence: Maciej Załuski, Collegium Medicum, Jagiellonian University, Kraków, Poland

E-mail: mzaluski@cm-uj.krakow.pl

Received: 05.10.2018; accepted: 12.01.2019; first published: 20.03.2019 of the interpersonal climate at work $[5,6]$. The stressors commonly present in the health service are supplemented by those specific for different medical specializations. They include, for example, very high requirements when working with patients in a critical health condition, conducting highly complicated surgical interventions, difficult intubations, work outside the hospital or outpatient clinic, the risk of occurrence of problematic relations with members of the medical team (e.g. during surgery or in psychiatric treatment) [7]. High mortality among patients, moral and ethical dilemmas connected with the life support of a patient, tense relationships with the patient's family, and exposure to traumatizing stressors are typical for emergency departments $[8,9]$. In palliative care, attention is drawn to the necessity for making ethically difficult decisions, continuous contact with a suffering person in the final phase of his/her life, and with death [10].

The occupational stressors combined with the level of subjective perceived stress, the ways of coping with stress and with personal and professional identification, together build the OBS-related factors. According to the multidimensional theoretical model, OBS is a psychological syndrome of emotional exhaustion, depersonalisation and reduced sense 
of self-accomplishment, and is understood as extended over time employee's reaction to the chronic impact of emotional, interpersonal and organizational stressors [11]. The burnout mechanism is connected with the lack of balance between the requirements of the work environment and personal resources (e.g. the level of subjective perceived stress and the coping strategies). Its sources may be rooted in the personal characteristics of an employee (personality traits), organizational factors (e.g. never being off-duty, lack of time to spend with family, social pressure, inadequate salary), social interactions (conflicts with patients and their families), operational aspects of work (e.g. having to cope with the injured and the dead, and exposure to human suffering) resulting in the condition of chronic tension and fear. The level of subjective perceived stress is a sign of failure in the coping with occupational stressors, using only passive ways of coping. The passive coping strategies, solely focusing on the methods to relieve mental pressure, does not change the ways of perceiving stressors.

The OBS syndrome contains involuntary or intentional reactions and behaviours used by the employee as a means of defence against the impact exerted by a stressor. The achievement of the intended purpose of overload protection, the Central Nervous System, is connected with a series of negative consequences, as a result of which the work performed so far with a sense of mission and vocation becomes - over time - only the execution of monotonous, boring and discouraging procedures. The progressive emotional loads gradually deprive an employee of his/her psycho-physical resources, thus initiating the occurrence of the next stages (symptoms) of the OBS [11]. The psychophysical exhaustion (PE) results in the emotional and cognitive distancing of doctors from patients and from the work they perform, in the form of negative emotionality, coldness and indifference, even cynicism (depersonalization DP), followed by a decrease in personal commitment to work giving rise to a decreasing sense of professional achievement and disappointment with work. There is a sense of the lack of ability to help others and professional failure (weakened sense of self-accomplishment). Use of the depersonalization mechanism is an attempt to protect oneself from increasing the consequences of exhaustion. The OBS symptoms can be understood as nonadaptive ways to reduce occupational stress.

According to Maslach and Leiter [11], if the employee is ill-fitted to the work environment, it creates a source of stress and increase a risk of developing occupational burnout. The model of job-person fit would seem to be an appropriate framework for understanding burnout. The correlation between the level of occupational burnout and the system of work performed was shown by Scarella et al. [12], indicating that a physician's availability on a $24 \mathrm{~h}$ basis and night-time work have a direct impact on the level of occupational burnout and the quality of life. The sources of ill-fit to the work are: an excessive number of administrative duties and rare participation in satisfying activities, a lack of support from the team and a lack of clear information about work tasks, and - what is particularly important - perception of work as stressful $[13,14,15]$.

All the predictors listed above are also organizational, operational and personal stressors in the workplace. Analyses of the results of scientific research carried out in 2010-2015 and earlier indicate that the risk factors for burnout include also younger age (junior doctors face greater pressure to increase knowledge and skills through practice), female gender (women are more likely to experience work-home conflicts), lack of a civil partnership, having children, although the results do not always confirm these relationships $[16,17,18]$. All the factors mentioned above, if they are not balanced by the employee's individual resources and organizational activities, increase risk the OBS.

As noted by West et al. [19], OBS among doctors has now reached epidemic levels. The report of a study of family doctors from 12 selected European countries published in 2008 , revealed a high level of emotional exhaustion in $43 \%$ of the doctors [20]. Results of an analysis of data reveal that more than a half of the doctors employed in American hospitals meet at least one criterion of OBS [21]. In 2018, the American Psychiatric Association presented information on its website that two out of five psychiatrists have symptoms of burnout. The number of medical doctors suffering from burnout increases every year (by 6\% over two years) [22]. The situation is similar worldwide (among others: Spain [23], Arab countries [24], and Poland [25].

Despite the growing scientific knowledge about the predictors of burnout among medical staff, as well as the introduction of preventive programmes in some countries, so far there has been insufficient evidence of the effectiveness of interventions [26]. There are data that emphasize the importance of individual ways of coping with stress as a way to protect against the development of OBS syndrome. Meta-analysis of 15 randomized trials conducted in the USA to assess the effectiveness of interventions aimed at preventing and reducing burnout in the group of physicians showed optimistic results [19]. The overall level of burnout was reduced by $10 \%$. There are data demonstrating the greater effectiveness of cognitive-behavioural interventions compared to various form of relaxation, and the lack of evidence in the case of encounter group in the form of Balint groups [27].

OBS develops insidiously, physicians often cope with OBS symptoms by undertaking additional duty at the hospital, which increases the level of psychophysical exhaustion. For this reason, it is postulated early recognition of the signs of burnout, maintaining a balance between work and family life, building social support networks, developing emotional intelligence, especially skills to deal with internal and external (interpersonal) conflicts, and replacing the biomedical model of burnout with a holistic model [22].

In 2013, at the request of the National Medical Council, a nationwide and representative questionnaire survey regarding physicians' opinion on working conditions, including signs of burnout, was carried out in Poland [28]. The survey showed that $42 \%$ of representative group of doctors examined, reported being occupational burned out, among whom the highest risk concerned men aged $35-50$ years and seniority 10-30 years, performing surgical procedures.

\section{OBJECTIVE}

The quantitative design plays a significant role in OBS research by using standardized psychological instruments to measure the signs of OBS syndrome, experienced stress and the effectiveness of coping with stress. For this reason, the aim of the study was an in-depth assessment of the level of OBS in a group of Polish doctors, and to confirm 
the relationship between the level of OBS and perceived stress scale (PSS) scores and other, selected risk factors and personal resources.

\section{MATERIALS AND METHOD}

A cross-sectional design was used with the application of a questionnaire method. The selection of the group had an intentional character: in order to include a person in the researched group, it was necessary that he/she was pursuing the profession of a medical doctor in Poland, both in public and non-public health service. The researched group covered persons from different regions of Poland, proportionally representing the doctors employed at large university hospitals, and at municipal hospitals and outpatient clinics in small healthcare centres. The criterion of exclusion from the group was: working as a doctor only on a part-time basis (less than full time employment, i.e. 15 hours a week), permanent employment abroad, citizenship and nationality other than Polish, psychiatric treatment (in particular, depression that required pharmacological treatment). The research was conducted online using the online medical portal, after having obtained the consent of the Bioethics Committee of the Jagiellonian University in Kraków. The research sample was randomly selected from the completion of volunteers who met the criteria for inclusion in the group. The medical portal contained information about the purpose of the planned tests, guarantee of confidentiality of the data received, and informed consent to participate in the study. From the group of people declaring willingness to participate in the study, 320 were randomly selected, and who were sent the questionnaires by e-mail. 318 correctly completed questionnaires were received (rate of return 99.37\%), two were discarded because of too many missing data. All participants were assured about the anonymity and confidentiality of their responses. For those interested, we offered an individualized e-mail with the results obtained in tests and proposed ways of stress reduction. The fillingin of the questionnaires was treated as an expression of informed consent to participate in the conducted research. Measurement was conducted in 2017.

The study involved 318 doctors: $66 \%$ women and $34 \%$ men, aged $27-86\left(\mathrm{M}_{\text {age }}=47, \mathrm{SD}_{\text {age }}=11.21\right) .62 \%$ of the respondents were first-degree specialists, $21 \%$ second-degree specialists, $3 \%$ had at least two specialties. 42 fields of medicine were represented in the study: psychiatry $-18 \%$ of respondents, internal medicine - $16 \%$, and paediatrics - 13\%. All participants in the study had academic degrees, the majority - 79\%, a Ph.D. in medical sciences.

A cross-sectional study with quantitative methodology was used by the application of a questionnaire method and correlation design. The following research tools were used: a proprietary questionnaire and two instruments translated into Polish: Link Burnout Questionnaire (LBQ) and Perceived Stress Scale-10 (PSS). The survey questionnaire, in addition to the basic demographic data, included questions regarding the place of employment and changes of place of work, management position in the workplace, frequency of being controlled by employees of the National Health Fund (NFZ), and the use of annual leave, having an account on a social network, having a pet and other hobbies, as well as taking antidepressants.
The LBQ questionnaire is the only OBS measurement psychological instrument recommended by the Polish Psychological Association, designed to measure burnout syndrome in healthcare professionals. The questionnaire has a norm table for doctors, and allows the recognition of four aspects of burnout (unlike the Maslach Burnout Inventory (MBI) formed by three scales): psychophysical exhaustion $(\mathrm{PE})$, commitment to relationships with patients $(\mathrm{CP})$, effectiveness in the performed work (EW) and existential expectations (EE). Santinello added disillusionment in existential expectations to the three scales proposed by Maslach, convinced of the high motivation that characterizes doctors in choosing their job [29]. PE is understood as the loss of energy resources, experiencing fatigue and tension during work. CP is expressed as a form of the conscientious and individual treatment of each patient. Its opposite is indifference, distancing and hostility. EW is the effectiveness of the tasks being performed. EE means passion and enthusiasm accompanying the work being done. Its opposite is disillusionment with the results. A respondent uses a 6-grade Likert-type scale for the assessment of 24 items ( 1 - never, 2 - rarely, 3 - once or several times per month, 4 - more or less every week, 5 - several times a week, 6 - every day). The raw result of each scale is obtained by summing-up the answer according to the key, and is included between $6-36$ pts. The higher the score, the greater the intensity of every aspects of the burnout syndrome. Cronbach's alpha - a coefficient of reliability for four sub-scales of the LBQ amounted in the presented study, to: psycho-physical exhaustion -0.82 ; commitment in relationships with patients -0.57 ; efficiency in the work performed- 0.76 ; existential expectations -0.88 .

The PSS-10 questionnaire is the most widely used psychological instrument for measuring the cognitive aspects of stress and coping, recommended by the Polish Psychological Association. Ten questions of PSS-10 identify the level of perceived stress as an indicator of the effectiveness of dealing with life events. The questions in the PSS ask about feelings and thoughts, the respondent answers on a 5-point Likert-type scale ( 0 - never, 1 - almost never, 2 - sometimes, 3 - quite often, 4 - very often). PSS scores are obtained by reversing responses six negatively stated items and then summing negatively i positively stated items. The overall raw result is included between $0-40$ pts. The higher the score, the greater the intensity of the perceived stress. The results allow the prediction of physical and mental discomfort in the respondents [30]. Cronbach's alpha - a coefficient of reliability, amounted in the current study to 0.89 .

Statistical analysis. The distribution of LBQ results was platycurtic: a left-skewed distribution for PE and CP subscales, while for the EW and EE subscales - right-skewed. The distribution of results PSS-10 was normal. An ANOVA variance analysis was performed on the obtained data. In the statistical analysis, parametric tests were performed on quantitative variables with a normal distribution, and nonparametric tests for quantitative variables with a distribution different from normal, and for qualitative variables - cross tabulation and $\mathrm{Chi}^{2}$. Analysis of the distribution of the variables: age, gender, marital status, and the number of years employment was close to normal or deviated from the normal; therefore, non-parametric tests were used. Computer support with the IBM SPSS Statistics 2.0 was used. 


\section{RESULTS}

Level of OBS in the study group. The first stage of the data analyses involved estimation of the intensity of the two main variables: the four dimensions of OBS and the level of perceived stress. The results of estimation of the OBS symptoms and the level of stress were encoded into sten scores.

Table 1. Descriptive statistics of the measurement of 4 aspects of OBS using the LBQ questionnaire

\begin{tabular}{ccccc}
\hline Aspects of OBS & Minimum & Maximum & M & SD \\
\hline $\mathrm{PE}$ & 6 & 36 & 22.07 & 6.69 \\
\hline $\mathrm{CP}$ & 6 & 36 & 18.40 & 4.88 \\
\hline $\mathrm{EW}$ & 6 & 34 & 17.03 & 5.82 \\
\hline $\mathrm{EE}$ & 6 & 36 & 17.70 & 7.66
\end{tabular}

OBS - occupational burnout syndrome; PE - psychophysical exhaustion (a high score indicates high level of exhaustion); CP - commitment to relationships with patients (a high score indicates a lack of commitment with patients); EW - effectiveness in the performed work (a high score indicates a lack of effectiveness); EE - existential expectations (a high score indicates disappointment at work)

In the subscales, $\mathrm{PE}$ and $\mathrm{CP}$ presented high scores, while in the subscales of EW and EE presented low scores. The average results for the group were in the following sten scale set for the doctors' professional group: PE -7 sten scores (range with a probability of $85 \% ; 6-9$ sten scores), CP - 7 sten scores (range with a probability of $85 \% ; 5-8$ sten scores), EW -7 sten scores (range with a probability of $85 \% ; 6-9$ sten scores), EE -8 sten scores (range with a probability of $85 \% ; 7-8$ sten scores). Table 2 presents the proportion of high results (8 sten scores and above) of OBS measurement in the examined group of doctors.

Table 2. Share of high results of OBS measurement in the examined group. $\mathrm{N}=318$

\begin{tabular}{ccl}
\hline Aspects of OBS & $N$ & $\%$ \\
\hline PE & 137 & 43 \\
\hline CP & 140 & 44 \\
\hline EW & 148 & 47 \\
\hline EE & 151 & 48 \\
\hline
\end{tabular}

OBS - occupational burnout syndrome; PE - psychophysical exhaustion (a high score indicates high level of exhaustion); $\mathrm{CP}$ - commitment to relationships with patients (a high score
indicates a lack of commitment with patients); EW - effectiveness in the performed work (a high score indicates a lack of effectiveness); EE - existential expectations (a high score indicates disappointment at work)

Level of stress experienced in the examined group. The average result of the measurement of subjectively felt stress in the examined group was 23.55 points. $(\mathrm{SD}=8.01$, empirical range: $2-40$ ). This is a value in the range of 8 sten scores. After calculating the median value ( $\mathrm{Me}=24.5$ points, 8 sten scores), the obtained results were allocated to two parallel subgroups with a stress level below and above the median value.

Correlation statistics - OBS due to the level of stress experienced. In the second stage, analysis of the correlation between main variables was performed. Then, due to the fact that PE is considered to be the source of other negative changes, the decision was made to further analyze only the mentioned aspect of professional burnout, and look for relationships with the other variables which were examined. In order to assess the differences in the intra-group within PE variable, the median criterion $(\mathrm{Me}=22)$ was used. A subgroup of results indicating low $(\mathrm{L})$ and high $(\mathrm{H})$ level of $\mathrm{PE}$ was separated. Group results differed statistically $\left(\mathrm{M}_{\mathrm{L}}=16.66, \mathrm{SD}_{\mathrm{L}}\right.$ $\left.\left.=4.32 ; \mathrm{M}_{\mathrm{H}}=27.55, \mathrm{SD}_{\mathrm{H}}=3.37\right), \mathrm{F}=626.86, \mathrm{df}=1, \mathrm{p}<0.001\right)$.

Application of the ANOVA method of analysis of variance showed the presence of significant differences in the value of four aspects of occupational burnout, taking into account the level of the experienced stress. $\mathrm{U}$ test values amounted to: $\mathrm{PE}=3720 ; \mathrm{p}<0.001 ; \mathrm{CP}=73971 ; \mathrm{p}<0.001 ; \mathrm{EW}=4722.5$; $\mathrm{p}<0.001 ; \mathrm{EE}=4940 ; \mathrm{p}<0.001$ (Fig. 1).

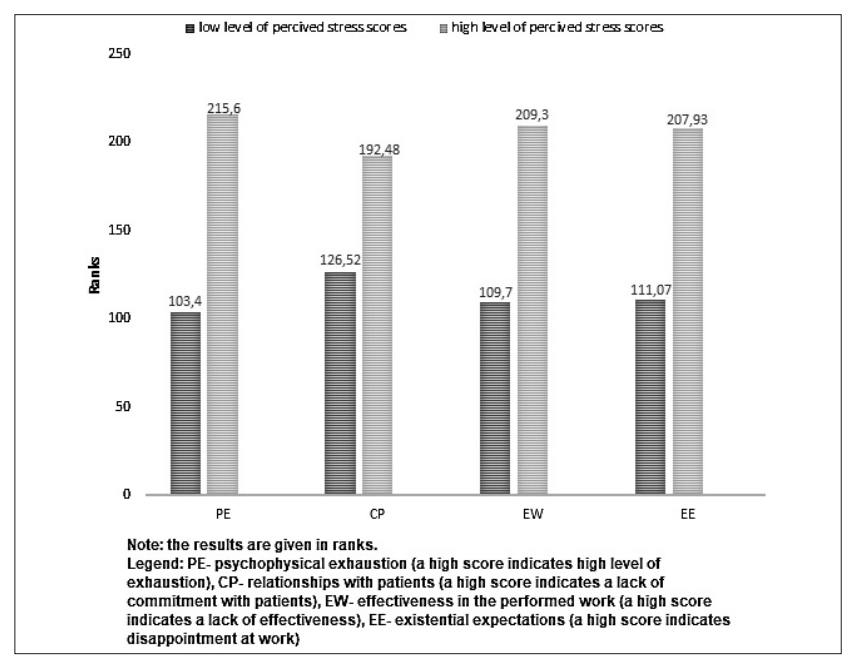

Figure 1. Results of the measurement of four aspects of OBS in two subgroups after calculating the median value of the stress level

PE and level of stress experienced. There were significant differences $(U=3820 ; p<0.001)$, a high level of PE co-existed with high levels of stress. In the subgroup with a low level of $\mathrm{PE}$, the average level of occupational stress was 104.4 points; in subgroup with a high level of $\mathrm{PE}-215.6$ points.

The third step of data analysis involved estimation of correlations between the PE variable and other independent variables: gender and marital status, practicing a medical profession, possessed hobbies and passions, frequency of using holiday leave, and others.

$P E$ and age of respondents, gender and marital status. In group $\mathrm{L}\left(\mathrm{M}_{\mathrm{L}}=48, \mathrm{SD}_{\mathrm{L}}=11.30\right)$ older people prevailed, in group $\mathrm{H}$, younger $\left(\mathrm{M}_{\mathrm{H}}=45, \mathrm{SD}_{\mathrm{H}}=10.95\right), \mathrm{t}=2.42, \mathrm{df}=316$, $\mathrm{p}=0,02$ ). There were no differences in the level of exhaustion when taking into account the gender and marital status of the respondents.

PE and variables related to practicing a medical profession. Differences between doctors with low and high levels of PE in variables related to the medical profession were checked. The basic workplace variable was excluded from the analyses because the vast majority of respondents worked in the public health service $(\mathrm{L}=285 ; 90 \%)$. The following results were obtained: in group L, the majority were doctors with longer seniority $(t=2.36, d f=316 ; p=0.02)$.

In group $\mathrm{L}$, the majority were physicians who should take up senior management and leadership roles in the health services $\left(\mathrm{Chi}^{2}=8.38, \mathrm{df}=1 ; \mathrm{p}=0.004\right)$. Since similar results were observed in the group of people with a high level of $\mathrm{PE}$, it should be recognized that team management is not a differentiating factor. 
$\mathrm{PE}$ and variables related to hobbies and passions. The majority of respondents had hobbies and passions. Although in group L more people than in group $\mathrm{H}$ declared having a passion, the differences were so insignificant that the mentioned factor cannot be considered as significantly related to the level of burnout $\left(\mathrm{Chi}^{2}=5.58, \mathrm{df}=1 ; \mathrm{p}=0.02 \mathrm{~V}=0.14\right)$.

PE and variables related to frequency of using holiday leave. Doctors from group L declared more frequent use of annual leave $\left(\mathrm{Chi}^{2}=18.11, \mathrm{df}=3 ; \mathrm{p}<0.001, \mathrm{~V}=0.24\right)$ (Fig. 2).

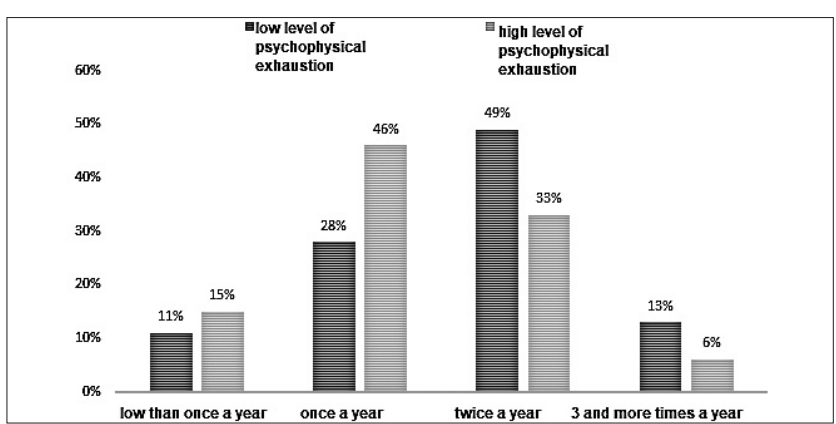

Figure 2. Frequency of using a holiday leave, taking into account the level of psychophysical exhaustion

There were no links between the level of psychophysical exhaustion and the number of years worked in the basic place of work, number of working hours per week, number of on-call duty hours per month, type of specialty, holding an academic title, number of jobs, change of employment, length of time of travel between places of employment, work abroad, and being controlled by the National Health Fund (NFZ). Also, having an account in a social network, having a pet, and taking antidepressants did not coincide with changes in the level of exhaustion.

\section{DISCUSSION}

The aim of the presented study was to assess the level of OBS in a group of Polish doctors, and to confirm the relationship between the level of burnout and the level of perceived stress and selected risk factors and personal resources. The obtained results of the measurement of four aspects of the occupational burnout in the examined group of doctors, in the case of psychophysical exhaustion, lack of commitment and ineffectiveness of undertaken professional activities, were on the verge of average and high values, while disappointment with work obtained high results. Every second examined physician declared a high level of OBS in each of the four aspects. These data are comparable to those obtained in a study of 181 doctors at the University Clinical Hospital in Wrocław, south-west Poland, where $74.6 \%$ of physicians, in at least one aspect, declared a high level of burnout [31]. The similarity in the results also applied to the scope of prevalence of a low degree of commitment to the relationship with a patient, and a sense of a lack of professional effectiveness. The obtained data are higher in all four aspects than those obtained in the LBQ adaptation questionnaire survey carried out in 2014 in Poland in a group of 199 doctors [29]

Also, in the case of the average value of perceived stress in the study group reached a high level. For comparison, the average result obtained in a group of 1,830 healthy
Poles was in the range of 5-6 sten scores (16.62 points, $\mathrm{SD}=7.50)$ [30]. The intensity of stress above the median value in the group of doctors examined co-occurred with a higher level of PE, less care for relations with patients, a lack of professional effectiveness and a greater degree of disappointment with work. The high score obtained in the PSS-10 questionnaire presented evidence that the actions undertaken by the examined person in coping with everyday stress were unsuccessful. There is no doubt that acute and chronic stress affects risk OBS. The level of PE depends on the degree of physician reactivity to stressful or emotionally challenging experiences. The goal is knowing how to perceive and respond to a stressor in ways that do not increase the risk of OBS. This is very important because chronic stressrelated disorders co-occur with OBS in the development of heart disease and HPA axis disorder, depression, and often fall outside the category disease and not treated at all.

There are links between cognitive assessment, psychophysiological reactions and symptoms of burnout. For example, medical workers who declare higher levels of OBS reported a higher severity of perceived stress and, at the same time, a higher level of cortisol secretion measured after waking up and before falling asleep [32]. The presence of the relationship between stress and OBS also confirms the effectiveness of prevention programmes focused on stress management. The stress reduction programmes, e.g. healing with suffering and stress management as well as contemplation-meditation exercises, debriefing sessions, and focus group that explored themes around work-related stressor and coping mechanisms, are examples of useful physicianrelated interventions to reduce OBS [19]. Strengthening the knowledge of medical doctors about the stressors and cognitive and behavioural ways of coping with stress seems to be as important as organizational changes in the healthcare centres.

The current study shows that a higher level of PE coincides with a younger age and shorter time of seniority. Analyses of the results of scientific research conducted in 2010-2015 indicate that the risk of burnout includes a younger age, unrealistic ideas about the possibilities of modern medicine, high expectations and motivation to work, typical for the first years of work [18]. Age and working hours may be linked through greater pressure to increase knowledge and lack of experience resulting in increased working hours. However, not all studies confirm these relationships, and the researchers point to difficulties in establishing a causal link, requiring longitudinal research [17].

Although in own research there were no links between the level of psychophysical exhaustion and the number of years worked in the basic place of work, number of working hours per week, number of on-call duty hours per month, the results show that in the group of 318 doctors, only $22 \%$ provided health services exclusively in one place of work, the majority, namely $52 \%$ in $2-3$ medical facilities, $21 \%$ in $4-5$, and $4 \%$ in more than 5 healthcare facilities. This fact is confirmed by other authors. In many cases, Polish doctors work more hours than a full-time job in a hospital, standardized by EU arrangements. $10 \%$ of doctors admitted to working 2-3 times longer than 1 FTE which is more than 10 hours a day, including weekends. $2 \%$ declare working 18 hours a day each day [33]. A meta-analysis of burnout predictors among psychiatric trainers from 22 countries showed that the odds ratio of severe burnout was higher with more weekly working hours (it increased by $9 \%$ with every additional hour), and 
not having regular 11 hours rest in every 24 hours (odds ratio of severe burnout was 38\% higher for those who did not have regular rest, compared to those who did have) [13].

The average weekly number of working hours of a Polish doctor is 44 hours. A large number of on-call duties, long working hours and work in various medical facilities are not the only occupational stressors. Another is the need to complete time-consuming medical records (writing prescriptions, sick leaves, filling-in personal data) and searching for medical history. As a result, the time of the average patient's visit to a doctor in outpatient care in Poland is 20 minutes, of which 16 minutes are organizational activities, and only 4 minutes are intended for examination and conversation with the patient. Patients notice this. $72 \%$ of them think that doctors devote too much time to completing medical records and too little to the diagnosis of the patient's health condition [34].

There is a paradox that persons who are burnt-out take extra duties instead of temporarily relieving themselves from work. The result obtained in the studies confirm the regularity mentioned above. The frequency of using holiday leave in the study group amounted to two holiday breaks a year. In the case of three breaks, there were twice as many people with low levels of exhaustion, compared with those suffering from a high level of exhaustion. The outcomes of meta-analysis of research on the prevention OBS indicate, that organizational-directed interventions were more likely to lead to reductions in burnout. These are a simple intervention in the form of load reduction, changes in work schedules, duty hour limitation policies [35].

The negative consequences of burnout are not limited to symptoms forming the syndrome, but relate to both individual and organizational effects. The organizational consequences of the burnout of medical workers are: low retention rate, i.e. the capacity of medical facilities to retain workers, high level of professional rotation, and emerging staff shortages The results of research conducted worldwide indicate that professional burnout results in a decrease in the productivity of doctors, measured by the number of days spent on sick leave, loss of the capacity to work, resignation from continuing in medical practice, and rotation between facilities.

Although in own research there were no links between the level of psychophysical exhaustion and changes in employment, the study confirmed a high level of professional rotation among Polish physicians: $44 \%$ of 318 doctors had changed their workplace, of which $26 \%$ at least once and $5 \%$ at least five times. $4 \%$ of physicians declared that they worked abroad in the past. Data from the Supreme Medical Council (NIL) in Poland indicate an increasing process of the outflow of medical personnel from the Polish labour market. According to estimates, around 30,000 Polish doctors may work abroad [36]. As Poland is not an attractive country for migrants, there is an increasing risk of a shortage of medical personnel [37]. According to the data of the Organization for Economic Cooperation and Development (OECD), in 2014, $1.8 \%$ of doctors working in Poland were foreigners, while the average for OECD countries was $17.3 \%$ [38]. According to a report published in 2016, there were 2.3 practicing doctors in Poland per 1,000 inhabitants in 2014 [39]. This is the lowest rate in the entire European Union, for which the average is 3.5. At the same time, however, doctors in Poland provide 7.3 consultations per year per 1,000 inhabitants. According to the estimated number of consultations per year per one doctor (3,121 consultations), Polish doctors are in third place in the EU (for comparison, the number in Norway is 971, and in Sweden 704 consultations).

The average age in the examined group of 318 physicians was 47 years, and among them were some aged 87 . The generation gap among Polish doctors deepens. According to the data of NIL, the average age of a practicing specialist is 55 years, while the number of specialties in all medical specialties is decreasing [40].

\section{CONCLUSIONS}

The research performed proved the high level of burnout in every second examined physician from an intentionally selected group of polish physicians. This is a result higher than that obtained in the survey conducted in 2013 by the Polish Chamber of Physicians and Dentists. The results of own research seem to be meaningful, given that only recently, in 2018, during the XIV National Congress Physicians in Warsaw, physicians adopted a resolution on the creation of mechanisms to prevent burnout among Polish doctors [41]. The coexistence of signs of OBS and high level of perceived stress, appraisal of a specific life situation and effectiveness of coping with stress, indicates the direction for preventive interventions. However, one should not think only about correcting the level of stress (relaxation, leave periods, limited working hours, improving psychosocial working conditions), changes should affect cognitive and emotional resources of physicians, such as perceived helplessness, self-efficacy, ability to tolerate unpleasant experiences, and resilience. It is reasonable to use cognitive-behavioural techniques to prevent stress and OBS symptoms, and take such organizational changes that increase the sense of professional and decisionmaking autonomy of the physician. This is consistent with the science literature' data on the relationship between OBS and the locus of control. The physician's ability to the stress manage (soft skills) should be evaluated on par with medical skills.

Confirmation in own research of the positive relationships between OBS and young age and seniority of the physicians,emphasize the need for early prevention, even in the last years of medical studies, at the latest in the first years of employments. It is necessary to stimulate employees to frequent use of holiday leaves, and especially to prefer a series of short leave periods in place of one longer one. It is necessary to change the mistaken belief of the majority of health care institutions that OBS and job satisfaction are solely the responsibility of individual physicians, while OBS is more a problem of the health care system than of an individual human. As Panaglioti stated in 2017: "Even though many studies have examined risk factors for burnout in physicians, relatively few intervention programme ave been developed and evaluated"[35].

Limitation. The study took into account selected sociodemographic factors influencing the incidence of the OBS syndrome. Finally, it is necessary to indicate the most important limitations of the studies carried out. Their cross-sectional design allowed only for the observation of the coexistence of some variables as risk factors for burnout, and it did not examine changeability of the OBS phenomenon. The study did not use objective methods that allow for the measurement of the medical parameters of burnout and stress, only questionnaire methods were used. The use of self-report questionnaires 
entails the risk of a number of measurement errors (reporting bias, method variance error and obtaining data from one source only, error of reverse causality). In order to be able to show directional relationships, further research requires the use of a longitudinal study and an experimental method.

The strength of the research was the use of a Internet platform to ensure confidentiality of the survey. The authors of the study are planning to take into account an analysis of personality factors (e.g. sense of self-efficacy, resilience) and variables connected with psycho-social working conditions (e.g. emotional labour).

\section{Conflict of interest}

The authors have no conflict of interest to declare.

\section{Funding}

The presented study did not receive the support from any grant.

\section{REFERENCES}

1. Pines A. Work burnout: Causes, results and ways of coping. Hebrew: Ben-Shemen: Modan Publishers; 2011.

2. Leka S, Jain A. Health impact of psychosocial hazards at work: an overview. Nottingham: World Health Organization; 2010: 30-62.

3. Gazelle G, Liebschutz J, Riess H. Physician Burnout: Coaching a Way Out J Gen Intern Med. 2015; 30: 508-513.

4. Tziner A, Rabenu E, Radomski R, Belkin A. Work stress and turnover intentions among hospital physicians: The mediating role of burnout and work satisfaction Revista de Psicología del Trabajo y de las Organizaciones. 2015; 31: 207-13.

5. Basu S, Qayyum H, Mason S. Occupational stress in the ED: a systematic literature review. EMJ 2017; 34: 441-447.

6. Pulcrano M, Evans SR, Sosin M. Quality of Life and Burnout Rates Across Surgical Specialties: A Systematic Review. JAMA Surg. 2016; 151(10): 970-978. https://doi.org/10.1001/jamasurg.2016.1647.

7. van der Wal R, Jacqueline Wallage J, Bucx M. Occupational stress, burnout and personality in anesthesiologists. Curr Opin Anaesthesiol. 2018; 31: 351-356. https://doi.org/10.1097/ACO.0000000000000587. (access: 2018.05.23)

8. Moss M, Good Vicki, Gozal D, Kleinpell R, et al. A Critical Care Societies Collaborative Statement: Burnout Syndrome in Critical Care Health-care Professionals: A Call for Action. Am J Respir Crit Care Med. 2016; 194: 106-113.

9. Mol M, Kompanje E, Benoit D, Bakker J, et al. The Prevalence of Compassion Fatigue and Burnout among Healthcare Professionals in Intensive Care Units: A Systematic Review. PLoS One 2015; 10: 8.

10. Fernandez_Sanchez J, Perez-Marmol J, Blasquez A, Santos-Ruiz A, et al. Association between burnout and cortisol secretion, perceived stress, and psychopathology in palliative care unit health professionals. Palliat Support Care 2018; 16: L 286-297, https://doi.org/10.1017/ S1478951517000244 (access: 2018.08.13).

11. Maslach Ch, Schaufeli W, Leiter M. Job burnout. Annu Rev Psychol. 2001; 52: 397-422.

12. Scarella T, Nelligan J, Roberts J, Boland RJ. Effect of call organization on burnout and quality of life in psychiatry residents. Asian J Psychiatr. 2017; 25: 27-30.

13. Jovanovic N, Podlesek A, Volpe U, Barrett E, Ferarri S, Rojnic, et al. Burnout syndrome among psychiatric trainees in 22 countries: Risk increased by long working hours, lack of supervision, and psychiatry not being first career choice. Eur Psychiatry. 2016; 32: 34-41.

14. Hudek-Knezevic J, Maglica B, Krapic N. Personality, organisational stress and attitudes toward work as a prospective predictors of professional burnout in hospital nurses. Public Health. 2011; 52: 538-549.

15. Levert T, Lucas M, Ortlepp K. Burnout in psychiatric nurses:contributions of the work environment and a sense of coherence. South Afr J Psychol. 2000; 30: 36-44

16. Lee R, Seo B, Hladkyj S, Lovell B, Schwartzmann L. Correlates of physician burnout across regions and specialties: a meta-analysis. Hum Resour Health. 2013; 11:48. hhtps:// doi.org/10.1186/1478-4491-11-48. (access: 2018.07.01).
17. Amoafo E, Hanbali N, Patel A, Singh P. What are the significant factors associated with burnout doctors? Occup Med. 2015; 65: 117-121. https:// doi.org/10.1093/occmed/kqu144. (access: 2018.08.13).

18. Sanfilippo F, Noto A, Foresta G, Santonocito C, et al. Incidence and Factors Associated with Burnout in Anesthesiology: A Systematic Review. Biomed Res Int. 2017. doi.org/10.1155/2017/8648925. (access: 2018.06.13).

19. West C, Dyrbye L, Erwin P, Shanafelt T. Interventions to prevent and reduce physician burnout: a systematic review and meta-analysis. Lancet 2016; 388: 2272-2281.

20. Soler J, Yaman H, Esteva M, Dobbs F, et al. Burnout in European family doctors: the EGPRN study. Fam Pract. 2008; 25: 245-65.

21. Babyar J. They did not start the fire: reviewing and resolving the issue of physician stress and burnout. J Health Organ Manag. 2017; 31: 410-417.

22. Meunier Y. Burnout, a Growing Occupational Risk for Physicians. IJCRIMPH 2016; 8: 307-308.

23. Yuguero O, Marsal J, Monserrat E, Soler-Gonzalez J. Occupational burnout and empathy influence blood pressure control in primary care physicians. BMC Fam Pract. 2017; 18: 63, https://doi.org/10.1186/ s12875-017-0634-0 (access: 2018.08.14).

24. Elbarazi I, Loney T, Yousef S, Elias A. Prevalence of and factors associated with burnout among health care professionals in Arab countries: a systematic review BMC Health Serv Res. 2017; 17: 491, https://doi.org/10.1186/s12913-017-2319-8 (access: 2018.08.14).

25. Gaweł-Dąbrowska D, Maciaszek J, Łuc D, Borowicz W, et al. [Differentiation of the level of professional burnout among medical staff of Wroclaw Medical University Hospital]. Public Health Forum 2017; 2:61-68 (in Polish).

26. Rama-Maceiras P, Jokinen J, Kranke P. Stress and burnout in anaesthesia: a real world problem? Curr Opin Anaesthesiol. 2015; 28(2): 151-8. https://do.org/10.1097/ACO.0000000000000169.27.

27. Clough B, March S, Chan R, Casey L, et al. Psychosocial interventions for managing occupational stress and burnout among medical doctors: a systematic review. Syst Rev. 2017; 6(1): 144. https://doi.org/10.1186/ s13643-017-0526-3.

28. Naczelna Izba Lekarska. [Working conditions, conflict of interest and assessment of the suitability of soft competences in the professional practice of doctors and dentists]. 2013. https://www.nil.org.pl/data/ assets/pdf_file/0008/93266/Raport.pdf. (access:2018.10,28 (Polish).

29. Jaworowska A. [LBQ. Link burnout Questionnaire]. Warszawa: Pracownia Testów Psychologicznych; 2014: p. 5-57 (in Polish).

30. Juczyński Z, Ogińska-Bulik N. [NPSR.Tools for measuring stress and for coping with stress]. Warszawa: Pracownia Test ów Psychologicznych; 2009.p. 11-21 (in Polish).

31. Gaweł-Dąbrowska D, Maciaszek J, Łuc D, Borowicz W, et al. [Differentiation of the level of professional burnout among medical staff of Wroclaw Medical University Hospital]. Public Health Forum 2017; 2:61-68 (in Polish).

32. Kakiashvili T, Leszek J, Rutkowski K. The medical perspective on burnout. Int J Occup Med Environ Health. 2013; 26(3): 401-412.

33. Konsylium24.pl/Rynek Zdrowia, [There is no clear decline in the number of hours worked by doctors during the week] 2018. http:// www.rynekzdrowia.pl/Finanse-i-zarzadzanie/Nie-widac-wyraznegospadku-liczby-godzin-przepracowanych-w-tygodniu-przezlekarzy,184451,1,.html: 05.06.2018.12:30 (access: 2018.08.13) (in Polish).

34. Kamiński Ł. [E-health report through the eyes of Poles]. Warszawa 2017. http://zdrowastrona.pl/images/articles/Raport_E-Zdrowie. pdf.0506.2018. 14:04 (access: 2018.08.13) (in Polish).

35. Panagioti M, Panagopoulou E, Bower P, Lewith G, et. al. Controlled Interventions to Reduce Burnout in Physicians: A Systematic Review and Meta-analysis. JAMA Intern Med. 2017; 177(2): 195-205. https:// doi.org/ 10.1001/jamainternmed.2016.7674.

36. Łada A, Segeś-Frelak J. [Medicine without borders? Skilled migrants in medical professions in Poland and Germany]. Warszawa: Fundacja Instytut Spraw Publicznych; 2017; 13-128 (in Polish).

37. Wrześniewska-Wal I. Mobility of Polish physicians. Probl Hig Epidemiol 2012; 93: 209-215.

38. OECD Health at a Glance 2015, https://doi.org/10.1787/health_glance2015-en (access: 2018.08.15).

39. OECD Health at a Glance: Europe 2016, https://doi. org/10.1787/9789264265592-en (access: 2018.08.15).

40. Krajewski R. [Doctors and dentists - specialists A.D. 2015]. Gazeta Lekarska. 2015; 6-7 (in Polish)

41. Naczelna Izba Lekarska [Resolution No. 13 XIV National Congress Physicians May 26, 2018, on the creation of mechanisms for prevention burnout among doctors] 2018 https://www.nil.org.pl/data/assets/ pdf_file/0020/129053/uz-13-wypalenie-zawodowe.pdf(Polish) (access: 2018.12.20). 